\title{
A MOBILE LOCATION-BASED SITUATED LEARNING FRAMEWORK FOR SUPPORTING CRITICAL THINKING - A REQUIREMENTS ANALYSIS STUDY
}

\author{
Abeer Alnuaim, Praminda Caleb-Solly and Christine Perry \\ University of the West of England, Bristol, UK
}

\begin{abstract}
This paper presents the requirements work carried out as part of developing an intervention to improve students' critical thinking skills using location-based mobile learning. The research emerged from seeking to identify ways of getting Interaction Design students into real world environments, similar to those in which they will eventually be designing, maximising their ability to identify opportunities for innovation.

The first stage in designing the system is to conduct a comprehensive requirements study to understand specific student and staff needs in the envisaged scenario. As part of the requirements study we were interested in identifying weaknesses in the current mode of teaching, as well as problems students currently experience in understanding key concepts. We found that students did not stay adequately focused on the task and failed to identify appropriate technologies. We also noted scope for further support with analysing their findings. This information is helping us to determine the type and nature of location-based hints and formative feedback that the system can provide to aid students' understanding of the context they are in.
\end{abstract}

\section{KEYWORDS}

Location-based, mobile learning, critical thinking, requirements analysis

\section{INTRODUCTION}

Since the early days of mobile learning research, there has been a wide debate on its exact definition. Various researchers have different interpretations. Many are eager to show that m-learning is not a reduced version of e-learning (Belshaw, 2011). Vavoula et al. (2004) have defined it as “Any sort of learning that happens when the learner is not at a fixed, predetermined location, or learning that happens when the learner takes advantage of learning opportunities offered by mobile technologies”. Furthermore, Woodill (2011) acknowledges that there is a shift in the perception of mobile learning, "Ten years ago, mobile learning was about displaying e-learning on a small screen". He argues that it allows learners to learn in an "anywhere, anytime” manner and to access information when needed.

The strength of mobile learning lies in taking advantage of the rapidly evolving scope of mobile technologies. Being able to sense the context and location of the learner has opened up a wide range of possibilities for researchers to create more engaging, contextualised and personalised learning activities, maximising the benefit of the learning experience. Personalisation is one of mobile learning's strengths. According to Kinshuk et al. (2009), personalisation could be acquired either by adapting to the learner's characteristics, learning styles, performance, and needs; or by adapting to the context in which the learning is taking place.

This paper presents the requirements work carried out as part of developing an intervention to improve students' critical thinking skills using location-based mobile learning. The idea for the research emerged from seeking to identify ways of getting Interaction Design students into real world environments, similar to those in which they will eventually be designing, in order to enhance their ability to identify opportunities for innovation. However, sending students out into real-world environments with a brief to be evaluative and analytical, without the presence of a teacher, can lead to a superficial and frustrating experience, especially for students with beginning levels of analysis and limited critical thinking skills. It is not always possible for 
teachers to accompany students, and moreover, rather than immediate input from teachers, prompts to provoke the development of their own thinking might be more beneficial.

In order to design the system, the first stage is to conduct a comprehensive requirements study to understand specific student and staff needs in the envisaged scenario. As part of this study we were interested in identifying weaknesses in the current mode of teaching and problems students experience in understanding key concepts. This information is helping us to determine the type and nature of location-based hints and formative feedback that the system can provide to aid students' understanding of the context they are in. It is important to ensure that students don't miss out on key areas that may help them with analysing the situation properly. The hints can also give them the beginning of the threads to developing innovative ideas, thus providing added value to the mobile-based learning system.

The next section of the paper draws on the literature to explain context-aware and location-based learning, and the relevance of situated learning and critical thinking to this study, summarising the related work in the area. This is followed by an outline of the research methodology detailing the requirements gathering process and insights gained and explaining how these have been incorporated into the initial prototype designs of the application.

\section{LITERATURE REVIEW}

\subsection{Context-Aware and Location-Based Mobile Learning}

Context-aware computing is a rapidly growing research area. It aims to promote a flowing interaction between humans and technology (Barkhuus and Dey, 2003), collecting information from the surroundings of the user to provide an understanding of what is currently happening (Naismith et al., 2004).

Abowd et al. (1999) defines a context-aware system as follows: "A system is context-aware if it uses context to provide relevant information and/or services to the user, where relevancy depends on the user's task". Context, according to Brown et al.'s (2010), is “the formal or informal setting in which a situation occurs; it can include many aspects or dimensions, such as location, time (year/month/day), personal and social activity, resources, and goals and task structures of groups and individuals".

Barkhuus and Dey (2003) define three levels of context-aware applications depending on the interactivity with the user:

1. Personalisation: the user determines the way the application behaves in a particular situation.

2. Active context-aware: the application changes the content independently, based on the sensor data.

3. Passive context-aware: the application presents the changed context, sensor data, to the user and lets him/her take control of decisions about how the application behaves.

Much research has shown the significance of context-awareness in education (Yau and Joy, 2009; Fisher et al., 2009; Ghiani et al., 2009; Bhaskar and Govindarajulu, 2010; Chiou et al., 2010). Fisher et al. (2009) argue that the use of mobile devices such as tablet PCs in education can enhance the teaching experience of lecturers, as well as the quality of the learning experience of students. Shih et al.'s (2010) research indicates that using mobile learning helped lower the cognitive load of students with low achievement rates.

A large area of context-aware mobile learning research has been focussing on museums and tours in providing information based on the person's location (Reynolds et al., 2010; Chiou et al., 2010; Yatani et al., 2004; Costabile et al., 2008; Park et al., 2007; Hsu and Liao, 2011). According to Reynolds et al. (2010) many students appreciated the contextual information offered by the mobile device which encouraged them to ask more questions. This enhanced their knowledge about the objects in the museum.

From a pedagogical perspective, context-aware and location-based mobile learning is clearly related to the situated learning theory: it is important to gain an understanding of this in order to learn how to optimise the development and implementation of context-aware and location-based applications.

\subsection{Situated Learning}

Lave and Wenger's (1991) situated leaning paradigm, states that the situation in which learning occurs has a great effect on learners. They argue that learning must not be abstract and out of context. It is situated, and takes place within the context, activity, and culture in which it occurs as a "legitimate peripheral 
participation” process. Lave and Wenger (1991) emphasise social communication and interaction as being significant parts of situated learning. Learning should be presented in an authentic setting supporting knowledge exchange between learners (Naismith et al., 2004).

Defining the key characteristics of situated learning can differ between disciplines and technologies (Yusoff et al., 2010). When designing situated learning using mixed reality technology, Yusoff et al. (2010) outline three main elements: authentic context, authentic activity/task, and users' collaboration. Lunce (2006), in designing situated learning using simulation, suggests four criteria for situated learning: a specific context that impacts learning must be defined; peer-based interactions and collaboration between students must take place; knowledge is tacit; and tools must be used to accomplish real-time objectives.

Herrington et al. (2000) propose the following elements for situated online-learning using multimedia: "authentic contexts and activities, access to expert performances and the modelling of processes, multiple roles and perspectives, collaborative construction of knowledge, coaching and scaffolding, reflection to enable abstractions to be formed, articulation to enable tacit knowledge to be made explicit, and integrated authentic assessment”.

In summary there is agreement that although technologies differ, for a successful learning experience, situated learning has to take place in an authentic setting, with authentic contexts and activities. Therefore it is vital that this research is aligned to, and integrated into real teaching and learning scenarios to ensure validity. Additionally, facilitating collaboration between learners can be an important enhancement of the learning experience.

\subsection{Critical Thinking}

As this research proposes to encourage and develop students' critical thinking and analysis, it is important to define what this means. There are several relevant definitions of critical thinking, some as early as Dewey (1933). However, for the purposes of this study one definition has been identified, that of Scriven and Paul (1987), who defined it as "the intellectually disciplined process of actively and skillfully conceptualizing, applying, analyzing, synthesizing, and/or evaluating information gathered from, or generated by, observation, experience, reflection, reasoning, or communication, as a guide to belief and action". Their definition shows a clear relation to Bloom's taxonomy, as it relates critical thinking to the three higher levels of the taxonomy (analysis, synthesis, and evaluation) (Duron et al., 2006). This definition emphasizes the multifaceted nature of critical thinking, expressed through a number of activities. These activities correspond to the assessed work carried by students in this study explained in section 3.1

\section{THE SITUATED LEARNING PROBLEM DOMAIN}

This intervention aims to resolve issues faced by students when learning in a real-world situation. The initial situated learning activity is being developed for a level 2 Human-Computer Interaction (HCI) module in the Department of Computer Science and Creative Technologies at the University of the West of England (UWE), Bristol. As part of their work for this module, students are required to evaluate and carry out a context-based analysis as part of a requirements gathering process for a computer-based system. The requirements gathering process is to explore opportunities for a technological intervention, and also to ensure that the solution developed will suit the particular situation/users; so the emphasis is on gaining a really deep understanding of this: the people involved, their activities and the context. The student designer needs to consider the question: 'what are the constraints and barriers within the situation that need to be addressed?'

To facilitate this, the PACT (People, Activities, Context, and Technology) framework is used to prompt students to consider specific categories in their analysis. The elements of the framework are described by Benyon et al. (2010):

1. People: they differ physically, psychologically, and in terms of their knowledge of technology.

2. Activities: they differ in terms of temporal aspects (response time, frequency of the activity, time pressure and peaks), cooperation, complexity, and safety-criticality.

3. Contexts: the different environments in which the activities take place encompass the organisational and social context and the physical environment. 
4. Technologies: these should reflect the specific issues identified in considering the previous elements. Features include input, output, communication, and content.

The students' brief is to go into specific environments relevant to their design task and to collect data regarding the first three elements of the PACT framework, using mainly observation, but also formal and informal interviews, questionnaires and focus groups. They then need to analyse critically the data collated in order to identify possible constraints and solutions.

As stated earlier, this research is seeking to investigate a mobile location-based system to support the students' activity. The next section details our findings from the requirements gathering work carried out.

\subsection{Research Methodology}

Requirement gathering is a significant part of any user-centred design (Lazar et al., 2010); it aims to establish a deep understanding of the situation, to refine the user requirements and identify the functional and non-functional requirements of an application. In order to improve validity, a range of approaches was used, enabling us to triangulate the findings as part of the analysis. The approaches include the analysis of the students' submitted assignments, observations of teaching and interviews with the lecturers. Figure 1 illustrates this approach.

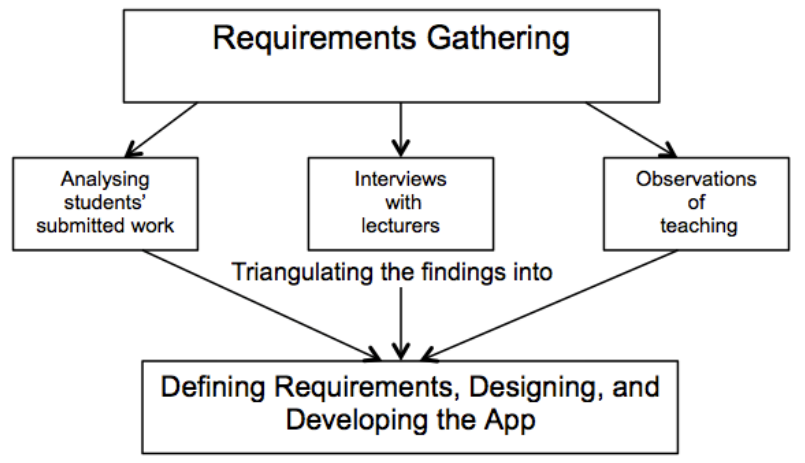

Figure 1. Requirements approach

\subsubsection{Analysing Students' Submitted Assignments}

Undergraduate students in their second year of the Web Design course in the Department of Computer Science and Creative Technologies at the University of West of England were required to submit a portfolio of small assignments. 47 out of 48 students submitted the part of their portfolio considered here. The work of these students was anonymised prior to analyses. Each student's work was separately scrutinised to identify his/her weaknesses and any good practice. It is crucial to know how common a particular issue is among the students to gain an understanding of whether that issue needs to be considered when designing and developing the application. The analysis was verified by checking its correspondence with written feedback from the lectures on each aspect of their work.

To anonymise the students, each was given a number from 1 to 47 . The table below shows the issues identified and occurrences, identified by the student number.

Table 1. Issues and occurrences

\begin{tabular}{|c|c|c|c|}
\hline $\begin{array}{l}\text { Issue } \\
\text { ID }\end{array}$ & Issues & Occurrences & $\begin{array}{l}\text { Total number } \\
\text { of students }\end{array}$ \\
\hline A & $\begin{array}{l}\text { No clear links of the issues discussed in } \mathrm{P}, \mathrm{A} \text {, and } \mathrm{C} \text { to } \\
\text { Technologies. }\end{array}$ & $\begin{array}{l}2,3,4,7,8,11,12,14,17,20,2 \\
2,24,26,27,29,34,45\end{array}$ & 17 \\
\hline $\mathrm{B}$ & Some issues were not related to the right element of PACT & $2,3,4,7,8,9,11,13,17,26,47$ & 11 \\
\hline $\mathrm{C}$ & No real consideration of the human factors. & $\begin{array}{l}3,4,10,13,22,23,28,29,35 \\
44\end{array}$ & 10 \\
\hline $\mathrm{D}$ & Issues were general and not mainly context related & $2,4,13,22,23,30$ & 6 \\
\hline $\mathrm{E}$ & $\begin{array}{l}\text { No links of the issues discussed in } \mathrm{P}, \mathrm{A} \text {, and } \mathrm{C} \text { with } \\
\text { Technologies. }\end{array}$ & $4,10,23,32,33,36,41,44$ & 8 \\
\hline
\end{tabular}




\begin{tabular}{|l|l|l|l|}
\hline F & $\begin{array}{l}\text { Gave the issue with the solution rather than putting the solution } \\
\text { under Technologies and linking it to P,A or C. }\end{array}$ & $\begin{array}{l}11,17,24,26,27,37,41,45,4 \\
6,47\end{array}$ & 10 \\
\hline G & Need more thoughtful consideration of the context & $12,29,32,41,44$, & 5 \\
\hline H & Need to address issues found under each PACT element. & $13,28,29$ & 3 \\
\hline I & Technology issues could be expanded & $16,17,35$ & 3 \\
\hline J & Linking should be more explicit & $18,19,21,30,46,47$ & 6 \\
\hline K & $\begin{array}{l}\text { Need to find solutions to current problems not eliminate ideas } \\
\text { because of that problem. }\end{array}$ & 28,19 & 2 \\
\hline L & $\begin{array}{l}\text { Need to think about and address issue from observations, } \\
\text { experience. }\end{array}$ & 28 & 1 \\
\hline M & $\begin{array}{l}\text { Need to identify issues under each P, A, C, and then see what T } \\
\text { can allow for the proposed self-checkout not for the cafeteria. }\end{array}$ & $31,32,34,35$ & 4 \\
\hline N & Need to consider human factors in more depth. & $33,34,35,41$ & 4 \\
\hline
\end{tabular}

In the table above we can see that $36 \%$ of the students had difficulties linking the characteristics of the people, activities, and context identified to technologies. In other words they should have identified the technologies that would serve the characteristics of the people carrying certain activities in that particular context. Moreover, 25\% of them had issues with understanding the PACT framework itself. However, it should be noted that the lecturers had not put a great deal of emphasis on this, as mentioned below in the section, Observations of Teaching. It is clearly important to consider the people who will be using the technology; nevertheless, $21 \%$ of students did not give this much attention. The chart below shows each issue with the corresponding percentage of students to whom this applies.

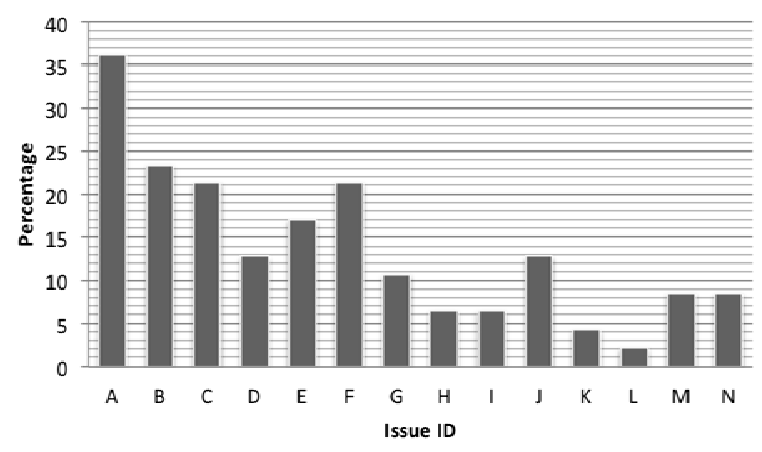

Figure 2. Percentages of the occurrences of issues

As future work we hope to organise a focus group to elicit further information about the difficulties encountered by students from a pragmatic point of view, and the functionalities that they would wish to see in the application to help them overcome these difficulties. We also hope to cross-reference this information with the information obtained from the students’ coursework analysis presented above.

\subsubsection{Interviews with Lecturers}

Our aim was to explore the following issues with the lecturers teaching the HCI module:

1. Their current practice of teaching students, especially concerning the PACT framework'

2. Their current approach to explaining assignment to students,

3. The students' current practice in completing the assignment, the difficulties they encounter, and the reasons behind these difficulties from the lecturers' point of view, and

4. What they hope this intervention will achieve.

A series of unstructured interviews with two lecturers teaching the HCI module was carried out. This is a significant part in the requirements gathering as it highlights clearly the functionality of the application that needs to be considered.

Current practice of teaching

In the Human-Computer Interaction module, students learn about how people undertake activities in context using technologies. They apply the PACT (People, Activities, Context, and Technology) framework to analyse situations in order for them to design interactive systems. The lecturers explain the PACT framework in detail to students giving them specific examples to clarify the concept. These include scenarios 
such as (a) a female student using her smart phone to send a text message whilst on a moving bus, when she is seated, when she is standing holding on to a bag and an overhead strap for balance, and when the bus is extremely crowded, and (b) and elderly woman setting her burglar alarm which is located in a dimly lit passageway, with situations where the elderly woman has different age-related conditions. These example scenarios are formulated to support the students in understanding the elements of the framework. Photographs are shown to provide students with a realistic view of the physical environment. However, the weakness is that the students are not able to immerse themselves in the actual environment to get a tangible understanding of the constraints, and therefore fail to develop empathy for the users.

Explaining the assignment to students

As part of one of their assignment activities, students are required to conduct a requirements study for the design of a new technology. In the past this has included the design of a university information kiosk and a digital guide for a music festival. This year students were asked to consider the design of a self-service checkout for use in a cafeteria. Using the 'PACT' framework, students were required to analyse the factors that they would need to take into account in designing such a system. They were required to gather data for the analysis via observations of the OneZone cafeteria (Main University Cafeteria at UWE) at various times, consider their own experiences, as well as conduct short interviews with at least 3 stakeholders.

Students were then required to present their findings as a mind-map/spider diagram, ensuring that there were clear links between the People, Activities and Context elements and the Technologies considered. They needed to explain in separate paragraphs and in relation to each element of the PACT framework, why the points that they had noted were of significance.

This was explained to the students in class and described on their coursework assignment specification alongside the marking criteria.

The students' current practice of the assignment from the lecturers' point of view

It is crucial to investigate the lecturers' understanding of the students' current practice of the assignment, the difficulties they encounter, and the reasons behind it from their point of view. Lecturers assume that students get distracted by the environment and sometimes forget the main purpose of their assignment. From their experience, students miss out key details when carrying out their analysis, leading to a disconnected analysis, especially between the elements of PACT. Moreover, students tend to forget that 'people undertake activities in context using technology'; as a result they fail to consider the implications of what they have identified for each of the elements, People, Activities, and Context, in relation to the Technology. They thus miss the purpose of their assignment, to analyse the situation and consider technologies that reflects peoples' needs when carrying out certain activities in a particular context. In some cases, students fail fully to engage with, or appreciate the relevance of going to the location at all, and complete the activity in a rushed manner with little or no reflection.

The lecturers' view of the intervention

The lecturers want this mobile application to assist students when carrying out their analysis. They want it to provide students with prompts when they are at the location. These prompts should address the students' weaknesses already identified by the lecturers and also from the analysis of the previous students' assignments, discussed earlier in the paper. The lecturers suggest that the students should be able to capture images using the application, take notes, and track their own progress.

\subsubsection{Observations of Teaching}

In addition to the interviews with lecturers, observation of teaching was conducted. This gave us a better understanding of the current practice. Attending HCI lectures was a valuable part of the research, giving an insight into how students engage with the lectures and what question they might raise about the PACT framework and the assignment. Observing the collaboration forum on Blackboard was also useful, revealing students' queries and concerns and the feedback given by the lecturer. Students expressed concern was about the elements of PACT and the relationship between the different elements. This raised significant questions that needed resolving. To what extent is it crucial to encourage students to use the PACT elements correctly? Is it a tool for bringing to light many factors or do we value it as a categorisation tool? It was important get back to the lecturers to discuss those two issues. It was agreed that we should remind students of the PACT elements without putting undue emphasis on categorisation. 


\subsection{Findings}

This section will explain the insights gained so far. It also explains how we are translating these into design features.

Students lose focus on the purpose of tasks when away from classroom. They may get distracted by their surroundings and miss out key elements. So a key feature of this mobile application could be to assist students of the purpose of their learning and support their progression through the activities in a personalised manner.

When students reach a pre-specified location, the application should display a detailed map identifying the various sub-locations and containing either text and/or images. These hints could be designed to aid them in widening their perspectives, in developing their own ideas and in critical evaluation. The text notes could vary from simple instructions and prompts, to questions, and in some cases to links that will open a quiz webpage; the particular content would depend on the specific aspect that the lecturer would want the students to focus on.

It is important to encourage students to think of issues beyond their own realm of experiences and perspectives. Providing students with functionality to share comments, ideas and perhaps stories if desired, may enable them to benefit from their peers' knowledge and different perspectives. Adding a collaborative learning aspect to the activity, students will be able to post their comments for their lecturers and fellow students.

Students have varying levels of ability when it comes to design thinking, and work at different rates. A mobile application provides opportunity for personalised learning, such as paced progression, checklists to give a sense of achievement and motivation, and structured disclosure, based on the students' level of interaction with the application.

Some students have been found to struggle in analysing their findings and specifically in using their findings to develop new ideas. Prompting them with probing questions that challenge their assumptions or get them to explore other methods of requirements gathering, beyond observation could help them identify innovative opportunities. This approach could also address the problem of their failing to identify appropriate technologies for the specific characteristics that they have identified earlier.

\section{CONCLUSION AND FUTURE WORK}

Research in mobile situated learning in higher education is still in its beginnings. Our research has potential to add to understanding of how mobile applications can assist students learning in-situ. This paper outlines the background to the research, discussing some key concepts. It focuses on the data obtained from the interviews conducted with the lecturers of the HCI module, the observations of teaching, and analysis of the students' submitted assignments; this data has confirmed the difficulties that students encounter whilst carrying out their coursework, helping us to establish the functional and non-functional requirements to be considered when designing and developing the mobile application. We are continuing with the research, adopting a user-centred, iterative approach to the design. We are currently working on the first prototypes of our application and will evaluate these, applying such usability criteria , as how easy the features of the application are to understand, its learnability, the effectiveness of feedback and the ease of interaction.

\section{REFERENCES}

Abowd, G., et al. (1999). Towards a better understanding of context and context-awareness. HUC '99 Proceedings of the 1st International Symposium on Handheld and Ubiquitous Computing, Karlsruhe, Germany. 304-307.

Barkhuus, L., \& and Dey, A. (2003). Is context-aware computing taking control away from the user? three levels of interactivity examined. Proceedings of UbiComp 2003, Seattle, Washington. 150-156.

Benyon, D. 2010, Designing Interactive Systems. 2nd edn, Addison-Wesley., Reading.

Bhaskar, N., \& and Govindarajulu, P. (2010). Advanced and effective learning in context aware and adaptive mobile learning scenarios. International Journal of Interactive Mobile Technologies, 4(1), 9-13.

Brown, E., et al. (2010). Location based and contextual mobile learning in deliverable contribution small scale study, STELLAR. 
Chen, C. -., \& \& Hsu, S. -. (2008). Personalized intelligent mobile learning system for supporting effective english learning. Educational Technology \& Society, 11(3), 153-180.

Chiou, C., et al. (2010). An adaptive navigation support system for conducting context-aware ubiquitous learning in museums. Computers \& Education, 55(2), 834-845.

Costabile, M., et al. (2008). Explore! possibilities and challenges of mobile learning. Proceeding of the 26th Annual CHI Conference on Human Factors in Computing Systems CHI 08, Florence, Italy. 145-154.

Dewey, J. 1933, How We Think, DC Heath and Co, Boston, MA.

Duron, R., et al. (2006). Critical thinking framework for any discipline. International Journal of Teaching and Learning in Higher Education, 17(2), 160-166.

Fisher, L., et al. (2007). Using situated learning theory to explore tablet pc use in academic work: Perceptions of staff and students. IADIS International Journal on Computer Science and Information Systems, 2(2), 99-109.

Ghiani, G., et al. (2009). UbiCicero: A location-aware, multi-device museum guide. Interacting with Computers, 21, 288303.

Guerreroa, L., et al. (2010). A mobile learning tool for improving grammar skills. Procedia - Social and Behavioral Sciences, 2(2), 1735-1739.

Hsu, H., \& Liao, H. (2011). A mobile RFID-based tour system with instant microblogging. Journal of Computer and System Sciences, 77(4), 720-727.

Hwang, G., \& Chang, H. (2011). A formative assessment-based mobile learning approach to improving the learning attitudes and achievements of students. Computers \& Education, 56(4), 1023-1031.

Hwang, G., et al. (2010). Development of a ubiquitous learning platform based on a real-time help-seeking mechanism. British Journal of Educational Technology, 42(6), 992-1002.

Hwang, G., at al. (2009). A context-aware ubiquitous learning environment for conducting complex science experiments. Computers \& Education, 53(2), 402-413.

Kelley, J.F., (1984), An iterative design methodology for user-friendly natural language office information applications. ACM Transactions on Office Information Systems, 2:1, pp. 26-41.

Kinshuk, Chang, M., Graf, S. \& \& Yang, G. 2009, "Adaptivity and Personalization in Mobile Learning.", In 2009 AERA Annual MeetingSan Diego, CA, USA., April 13-17.

Lave, J., \& Wenger, E. (1991). Situated learning: Legitimate peripheral participation. Cambridge: Cambridge University Press.

Lazar, J., et al. (2010). Research methods in human-computer interaction. West Sussex, UK: Wiley \& sons LTD.

Lunce, M. L. (2006). Simulations: Bringing the benefits of situated learning to the traditional classroom. Journal of Applied Educational Technology, 3(1), 37-45.

Naismith, L., et al. (2004). Literature review in mobile technologies and learning No. 11). Bristol: NESTA FutureLab.

Park, D., et al. (2007). A context-aware smart tourist guide application for an old palace. Proceedings of the 2007 International Conference on Convergence Information Technology (ICCIT '07), 89-95.

Reynolds, R., et al. (2010). Web-based museum trails on PDAs for university-level design students: Design and evaluation. Computers \& Education, 55(3), 994-1003.

Rogers, Y., Sharp, H. \& Preece, J. 2011, Interaction Design: Beyond human-computer ineraction, 3rd edn, Wiley \& sons LTD., West Sussex, UK.

Ryu, H., \& and Parsons, D. (2008). A learner-centred design of a location-aware learning reminder. Int. J. Mobile Learning and Organisation, 2(2), 187-200.

Scriven, M. \& and Paul, R.W. 1987, "Critical Thinking as Defined by the National Council for Excellence in Critical Thinking", 8th Annual International Conference on Critical Thinking and Education Reform, Summer 1987.

Shih, J. L., et al.. (2010). An inquiry-based mobile learning approach to enhancing social science learning effectiveness. Educational Technology \& Society, 13(4), 50-62.

Vavoula, G. N., et al. (2004). Producing guidelines for learning, teaching and tutoring in a mobile environment. 2nd IEEE International Workshop on Wireless and Mobile Technologies in Education (WMTE), Taoyuan, Taiwan. 173176.

Yatani, K., et al. (2004). Musex: A system for supporting children's collaborative learning in a museum with PDAs. Paper presented at the Wireless and Mobile Technologies in Education, 2004. Proceedings. the 2nd IEEE International Workshop, 109-113.

Yau, J. \& Joy, M. (2008) A Self-Regulated Learning Approach: A Mobile Context-aware and Adaptive Learning Schedule (mCALS) Tool. International Journal of Interactive Mobile Technologies, vol. 2, no. 3, pp. 52-57.

Yau, J. \& Joy, M. (2009) A Mobile and Context-aware Learning Schedule Framework from a pedagogical perspective an interview study. IADIS International Conference Mobile Learning, pp. 189-196, Barcelona, Spain. 